\title{
Compassion for others, self-compassion, quality of life and mental well-being measures and their association with compassion fatigue and burnout in student midwives: a quantitative survey
}

\begin{abstract}
Background: Compassion fatigue and burnout can impact on the performance of midwives, with this quantitative paper exploring the relationship between self-compassion, compassion fatigue, self-judgement, self-kindness, compassion, professional quality of life and well-being of student midwives.

Method: A quantitative survey measured relationships between self-compassion, compassion fatigue, well-being, and burnout using questionnaires: (1) Professional Quality of Life Scale; (2) Self-Compassion Scale; (3) Short Warwick and Edinburgh Mental Wellbeing Scale; (4) Compassion For Others Scale.

Participants: A purposive and convenience sample of student midwives $(n=103)$ studying at university participated in the study.

Results: Just over half of the sample reported above average scores for burnout. The results indicate that student midwives who report higher scores on the self-judgement subscale are less compassionate towards both themselves and others, have reduced wellbeing, and report greater burnout and compassion fatigue. Student midwives who report high on measures of self-compassion and well-being report less compassion fatigue and burnout.

Conclusion: Student midwives may find benefit from 'being kinder to self' in times of suffering, which could potentially help them to prepare for the emotional demands of practice and study.

Implications: Developing, creating and cultivating environments that foster compassionate care for self and others may play a significant role in helping midwives face the rigours of education and clinical practice during their degree programme.
\end{abstract}

Key words: burnout, compassion fatigue, student midwives, self-compassion, wellbeing, self-judgement 


\section{Compassion for others, self-compassion, quality of life and mental well-being measures and their association with compassion fatigue and burnout in student midwives: a quantitative survey}

\section{Introduction}

The journey to become a midwife involves demanding workloads, challenging placements, and witnessing of traumatic events, with consequent stress sometimes affecting compassion fatigue and burnout. Examples include, working with women who experience perinatal bereavement (Hollins Martin \& Forrest, 2013; Hollins Martin et al., 2013, 2014), those who relinquish their baby for adoption (Mander, 2000), or traumatic birth (Leinweber \& Rowe, 2010; Mollart, 2011; Sheen et al., 2013). In acknowledgement of such stressors, the British Medical Association (BMA, 2011) and the Nursing and Midwifery Council (NMC, 2015) recommend that a key element of health provision is to cultivate an environment that fosters compassionate care.

In an effort to explore this topic, a literature search was undertaken to find out what was already known about compassion in midwifery practice. A narrative review provided an overview which informed that some worries in relation to compassion and midwives in fact exist. Brettle and Grant's (2004) search strategy guidelines were followed, with key words including: compassion, midwives, midwifery, stress, compassion fatigue, burnout, and self-compassion. Databases explored included MEDLINE (R), PsychINFO, PsycARTICLES Full Text and PsycEXTRAand CINAHL. Since the authors wished to include both quantitative and qualitative methods, a strict hierarchy of evidence was not applied. The motivation was simply to capture a wide variety of relevant literature relevant to the area of interest. What follows is an appraisal of aspects of compassion to underpin the value of conducting the study. 


\section{Compassion}

Religious scholars perceive that compassion involves being charitable towards others (Barad, 2007). In contrast, the psychological sciences view compassion as recognising own or another's distress, and making an attempt to alleviate it (Gilbert, 2009). Empathy, distress tolerance, and kindness are key attributes of compassion, with self-kindness associated with reduced self-criticism, blame and worry (Neff, 2003; Gilbert \& Procter, 2006). Self-compassion has its roots in Buddhist teachings, with research substantiating its link with psychological well-being (e.g., Neff, 2003; Neff, et al., 2005; Leary et al., 2007; Hutcherson et al., 2008; Lutz et al., 2008; Gilbert, 2009; Kelly et al., 2009; 2010; Beaumont et al., 2012; Germer \& Siegel, 2012; Beaumont \& Hollins Martin, 2013, 2015). Mindfulness, empathy and loving kindness are factors that cultivate self-compassion and promote self-care and well-being (Raab, 2014).

Much debate has surrounded difficulties with health care professionals delivering compassionate care in healthcare settings (Care Quality Commission, 2011; Brown et al., 2013; Crawford et al., 2013, 2014). High levels of self-compassion and compassion for others has been linked with lower levels of compassion fatigue and burnout (Figley, 2002; Beaumont et al., 2015), with higher levels of selfcompassion post-therapy linked to reduced trauma symptoms (Beaumont et al., 2012; 2013), low mood (Gilbert \& Proctor 2006), and psychosis (Mayhew \& Gilbert, 2008; Braehler et al., 2012). Self-compassion exercises have been shown to reduce cortisol levels and increase heart-rate variability, which are linked with an ability to self-soothe when stressed (Rockliff, et al., 2008). Individuals who score:

- High on self-compassion are equally kind to others (Neff, 2003)

- Low on self-compassion are kinder to others than self (Neff, 2003; Neff \& Germer, 2012) 
As such, self-compassionate midwives are more likely to present with greater empathy for a childbearing woman's suffering through their appreciation of shared unity of pain (Şenyuva, et al., 2013). A positive correlation between self-compassion and emotional intelligence was identified in nurses ( $n=135)$ (Hefferman et al., 2010), with an absence of self-compassion rendering carers less able to convey authentic compassion towards patients. Although participant numbers in the Hefferman et al. (2010) study are small, results indicate the worth of further exploration, particularly into the area of compassion fatigue and burnout in midwives.

\section{Compassion fatigue and burnout}

Compassion fatigue is personal suffering that results from stress aroused through working with trauma (secondary traumatic stress) (Figley, 1995), or the reality of practice being mismatched to beliefs about care (Blomberg \& Sahlberg-Blom, 2007). Compassion fatigue has been diagnosed in doctors (Joinson, 1992; Pfifferling \& Gilley, 2000; Benson \& Macgraith, 2005), nurses (Sabo, 2006), and midwives (Leinweber \& Rowe, 2010). Experiencing, high levels of empathic relationships with childbearing women can place midwives/student midwives at risk of secondary traumatic stress (Leinweber \& Rowe, 2010; Davies \& Coldridge, 2015). Symptoms of compassion fatigue include (Figley, 1995):

- Lack of empathy/sympathy

- Irritability/anger

- Hyper-arousal

- Intrusive thoughts,

- Anxiety

- Increased alcohol consumption 
- Trepidation of working with some patients

Women are more at risk of developing compassion fatigue than men (Sprang et al., 2007).

In contrast to compassion fatigue, burnout is the physical and emotional exhaustion that occurs in practitioners from working in stressful environments (Figley, 1995). Maslach and Leiter $(1997 ; 2008)$ propose three dimensions of burnout, which include: (1) Exhaustion, (2) Cynicism, and (3) Inefficacy. In relation to exhaustion, out of $(n=56)$ midwives, $60.7 \%$ were found to be experiencing high levels of exhaustion and $30.3 \%$ burnout (Mollart et al., 2011). A further study reported that $56 \%$ of nurses working in acute medicine, and $20 \%$ in Accident and Emergency reported emotional exhaustion (Gillespie \& Melby, 2003). The authors conclude that regular encounters of work related stress may cause nurses to lose their ability to respond empathically to their patients. One limitation of these studies is the small participant numbers. Nonetheless, they indicate a problem worthy of further exploration. Using a larger sample size, Bakker et al. (1996) reported an association between increased workload and burnout in Dutch midwives $(n=200)$, concluding that implementation of policies to reduce burnout should be employed.

Together, burnout and compassion fatigue reduce attention, concentration, ability to communicate, and they contribute towards development of heart disease, mental health problems, and obesity (Miller et al., 1988; Spickard et al., 2002). Also, exposure to continual change, cutbacks, increased workloads, and pressure to meet NHS targets augment pre-existing stress in midwives (lles, 2011; Kirkham, 2007; Todd et al., 1998), with workplace settings, personal trauma, and role type all influencing potential for the midwife to develop compassion fatigue and burnout (Ray et al., 2013; Sheen et al., 2013). Continuous exposure to distressing situations and lack of control 
can increase student midwives susceptibility to developing compassion fatigue and burnout (Abendroth \& Flannery, 2006), with Yoshida and Sandall (2013) arguing that effective team-work, managerial support, job control and job satisfaction are key factors in relation to predicting burnout in midwives (Yoshida \& Sandall, 2013). When faced with stressors, some student midwives excessively smoke, consume alcohol, or comfort eat, whilst others implement positive approaches towards health, such as implementing mindfulness, writing diaries, or seeking help (Davies \& Coldridge, 2015).

Clearly, a combination of factors can lead to compassion fatigue and burnout in student midwives, with point made that when a student midwife's threat system is in a persistent state of activation, compassion may be hindered (Gilbert, 2009). A compounding problem is that compassion fatigue and burnout are strongly associated with anxiety and depression in nurses (Hegney et al., 2013), with mental well-being a significant predictor of staff turnover (Brunetto et al, 2013). In essence, the optimal aim of midwifery lecturing staff and clinical mentors is for student midwives to be high on compassion and low on burnout and fatigue.

\section{$\underline{\text { Rationale }}$}

Evidence has shown that working in stressful environments can cause student midwives to overlook their own emotional and psychological needs. In addition, student midwives are set stressful challenges by higher education institutions (Robotham \& Julian, 2006), which have potential to impact upon academic performance and mental health (Andrews \& Wilding, 2004; Figley, 1995). The literature review has highlighted a lack of research that has explored the impact of secondary traumatic stress and burnout in midwives, with little known about relationships between self-compassion, compassion, and quality of professional life in student midwives. In response, the aim of the present study was to explain self- 
compassion, self-kindness, self-judgement and their effects upon compassion, selfcriticism, compassion fatigue and burnout in student midwives.

\section{Methodology}

A quantitative survey measured compassion, self-criticism, compassion fatigue and burnout in trainee midwives using 4 validated questionnaires. A quantitative survey was selected because it is an effective and systematic method that can engage a sizable population (Polit \& Hungler, 1999). Surveying can provide a snapshot of the target population to establish a baseline from which the researcher can compare results (Field, 2013).

\section{$\underline{\text { Recruitment }}$}

Student midwife recruitment was from classes engaged in face-to-face education in the university classroom. MD and CJHM provided information and facilitated data collection. An information sheet and consent form was given to each student, followed by a brief presentation and question/answer session. Students were offered the opportunity to opt out at any time during process with no expectation of an explanation or penalties implied, in keeping with the principles of Johnson and Long (2007). Only one student midwife opted out, voluntarily explaining that she felt completely exhausted and had been caught in traffic in attempts to make the lecture on time. Participants were given a contact number in the event that they wanted to know their scores, and counselling was offered by an accredited psychotherapist (EB), with no uptake.

\section{$\underline{\text { Participants }}$}

A purposive and convenient sample of student midwives $(n=103)$ from a university in the north-west of England (UK) participated in this study. All participants were female 
and aged between 19-56 years; $(n=34)$ were in first year, $(n=54)$ in second year, and $(n=49)$ in third year of their midwifery degree programme.

\section{Ethical considerations}

Ethics approval was afforded by the University Ethics Committee, in line with the British Psychological Society guidelines of appropriate ethical practice. To limit fear of identification, participants were afforded complete anonymity, with questionnaires tagged with a number.

\section{$\underline{\text { Data collection }}$}

A quantitative survey was conducted using the subsequent 4 validated scales: (1) compassion, (2) self-criticism, (3) compassion fatigue, and (4) burnout in student midwives:

\section{(1) Compassion-for-Others-Scale}

The Compassion-for-Others-Scale (Pommier, 2011) consistes of 24-items (e.g., Q = When people cry in front of me I usually don't feel anything at all), and is subdivided into 6 subscales; (1) kindness, (2) indifference, (3) common humanity, (4) separation, (5) mindfulness, and (6) disengagement. Participants respond to items on a 1-5 Likert scale $(1=$ almost never $\& 5=$ almost always), with indifference, separation, and disengagement items reverse-scored. Cronbach alpha's for overall scale $=0.9$, with kindness $=0.77$, indifference $=0.68$, common humanity 0.7 , separation 0.64 , mindfulness $=0.67$, and disengagement 0.57 . Content, convergent and discriminant validity of the Compassion-for-Others-Scale is supported in USA populations (Pommier, 2011).

(2) $\underline{\text { Self-Compassion-Scale-Long-Version }}$ 
The Self-Compassion-Scale-Long-Version (Neff, 2003) consists of 26-items that measure typical action towards self during difficult times (e.g., $Q=$ I'm disapproving and judgemental about my own flaws and inadequacies, and $Q=I$ try to be loving towards myself when I feel emotional pain). The scale consists of 6 subscales: (1) selfkindness, (2) self-judgement, (3) mindfulness, (4) common humanity, (5) isolation, and (6) over identification, with items scored on a Likert scale $(1=$ almost never \& $5=$ almost always). Cronbach's alpha's for the overall scale $=0.93$, kindness $=0.88$, selfjudgement $=0.88$, common humanity $=0.80$, isolation $=0.85$, mindfulness $=0.85$, and over-identification $=0.88($ Neff et al., 2007).

\section{(2) Professional-Quality-of-Life (ProQOL) scale}

The ProQOL scale (Stamm, 2009) consists of 30 -items that measure positive and negative aspects of working with trauma in the workplace (e.g., $Q=$ I feel connected to others), and consists of 3 subscales: (1) compassion satisfaction, (2) compassion fatigue/secondary traumatic stress and, and (3) burnout. The ProQOL consists of 30items scored in relation to the preceding 30 days using a Likert scale $(1=$ never $\& 5=$ very often). Cronbach's alpha's for the overall scale $=0.88$, with burnout $=0.75$, and compassion fatigue/secondary traumatic stress $=0.81$. The ProQOL scale has been effectively validated in $>200$ papers (Stamm, 2010).

\section{(4) Short-Warwick-and-Edinburgh-Mental-Well-Being-Scale (sWEMWBS)}

The sWEMWBS is a 7-item short version of the 14-item Warwick-and-Edinburgh Mental-Well-being Scale, which is used to access participants perceptions of wellbeing over the preceding 2 weeks (e.g., l've been feeling optimistic about the future). Items are scored on a Likert scale $(1=$ none of the time $\& 5=$ all of the time $)$. 
Cronbach's alpha's for the overall scale $=0.8$, and the $s W E M W B S$ has been validated for use in UK populations (Tennant et al., 2009).

\section{Results}

Data for the mean and standard deviation scores for the 4 questionnaires are presented in Table 1.

\section{TABLE 1}

Scores on the Compassion-for-Others-Scale (3.86) were closer to the 'almost always' range (5), which according to Pommier (2011) can be considered a high score. Mean scores for self-compassion were (2.89), self-kindness (2.61), and self-judgement (3.34), all of which are considered to be within moderate range (Pommier, 2011).

Percentage scores as measured by the ProQOL scale (compassion satisfaction, compassion fatigue, and burnout) are presented in Table 2. For the present sample of student midwives, well-being was within the average range for UK populations (24.6) (Evans et al., 2015).

\section{TABLE 2}

Further analysis using Pearson's correlations indicates that over half the sample had a burnout score of average or above, with $40 \%$ reporting similar scores for compassion fatigue. In response, we explored the impact of these scores relative to the other measures. To view correlational analysis between scores for each measure see Table 3.

\section{TABLE 3}

Self-judgement was significantly negatively correlated with compassion for others $(r=-.216)$, and well-being $(r=-.374)$. A positive relationship was observed between self-judgement scores and compassion fatigue $(r=.233)$ and burnout $(r=.28 .3)$. This 
result suggests that when student midwives judge themselves harshly they also become less compassionate to self and others. In addition, they experience reduced well-being, and report greater burnout and compassion fatigue.

Conversely, self-kindness was found to be associated with less burnout $(r=-.203)$ and greater well-being (.408), and self-compassion scores were associated with low burnout $(r=.312)$, increased well-being $(r=.382)$ and compassion satisfaction $(r=.201)$. Compassion satisfaction scores positively correlated with scores on wellbeing $(r=.467)$ and self-compassion $(r=.207)$, and inversely with burnout $(r=-.593)$ and compassion fatigue $(r=-.412)$.

These results suggest that student midwives who report greater compassion satisfaction, encounter better well-being, greater self-compassion, fewer symptoms of burnout, and experience less compassion fatigue.

Self-judgement scores were divided into two categories (High versus Low), specifically to investigate if any difference could be found between ProQOL measures, compassion, and well-being. To view comparison scores between high and low selfjudgement in relation to all other scales (see Table 4).

\section{TABLE 4}

Results indicate significant statistical differences, indicating that when self-judgement scores are high, student midwives report less compassion for others, increased burnout, and lower personal well-being. No significant difference was found between measures of compassion fatigue and compassion satisfaction.

\section{Discussion}

Results show that high self-judgement is significantly negatively correlated with compassion for others, self-kindness, and well-being. In addition, a positive 
relationship was observed between self-judgement scores and compassion fatigue and burnout. These results reinforce the idea that when student midwives judge themselves unsympathetically, they become less compassionate to self and others, which results in reduced well-being, greater burnout and compassion fatigue. This set of results is in keeping with the findings of Mollart et al. (2011) who found that $40 \%$ of midwives reported average or above average burnout scores. Likewise, Yoshia and Sandall (2013) found that over $50 \%$ of midwives report significantly high levels of burnout, which supports that it is not only prevalent during midwifery training, but also post-registration. Moreover, our participants reported above average scores of compassion fatigue.

A surprising finding was the high levels of self-judgement amongst student midwives. One explanation could be that student midwives feel pressurised by a system that places more emphasis on hospital targets, and less on childbearing women's individualised needs (Kirkham, 2007). Gilbert (1997) proposes that selfblaming and self-criticism arise from efforts to improve self or prevent mistakes. Considering that midwives work in life threatening situations and operate in highly pressurized environments, they may become more self-attacking and self-punishing in their judgements of self-performance in attempts to improve standards and/or prevent errors (Gilbert, 2002). A hazardous environment can foster fear that ignites the endocrine 'threat system', which potentially could be deactivated by teaching selfsoothing strategies to restore harmony and compassion for self and others (lles, 2011).

In conjunction, high mean self-judgement scores may reduce levels of selfcompassion in response to threat, because fear of outcomes overrides selfcompassion and compassion for others. This idea is reinforced by the self-kindness 
and compassion scores, which were found to be associated with less burnout, greater well-being, and compassion satisfaction. Compassion satisfaction scores positively correlated with scores on well-being and self-compassion, and inversely for burnout and compassion fatigue. Student midwives who enjoy their work reported greater wellbeing, higher levels of self-compassion, lower levels of burnout, and compassion fatigue.

\section{Developing a culture of compassion}

Developing self-compassion by learning to self-soothe in times of stress could potentially reduce risk of compassion fatigue and burnout, at the same time as increasing personal well-being (Boellinghaus et al., 2012). This idea is in keeping with Leary et al. (2007) who identified that individuals who demonstrate self-compassion when suffering are less likely to become stressed or develop mental health problems. In addition, individuals with high emotional resilience are less concerned about failure and demonstrate more effective coping strategies in troubled times (Neely et al., 2009).

Including compassionate mind training, mindfulness practice and/or stress reduction programmes into student midwifery curriculum could potentially help student midwives develop self-compassion, empathy for their own suffering, and build resilience, which is an area that requires further study. Davies and Coldridge (2015) reported that students felt there was lack of training on subjects such as stress and how to cope in traumatic situations. Introducing self-care strategies that attempt to reduce self-criticism and challenge negative self-talk may also help student midwives cope with placement demands. Benefits accrued from developing a compassionate mind are well documented (see Leaviss \& Uttley, 2014; Beaumont \& Hollins-Martin, 2015). 
The merits of developing self-compassion to reduce stress and develop coping strategies during midwifery programmes could potentially prepare student midwives to manage stressors, promote self-care, improve compassionate care offered to others, and reduce self-criticism in both the workplace and at home. Such action could work towards improving quality of life, and help create compassionate environments for students and practitioners (Crawford et al., 2014).

\section{Limitations}

There are a number of limitations of this study. First, although students were on placement in a variety of clinical settings, the data collected was gathered from only one institution. Second, gathering survey data at longitudinal points (e.g., start, beginning \& end of training) would have provided richer information about direction of changes across time. Third, triangulating findings with a qualitative component would have enriched findings in terms of subjective experience. Fourth, participants may have chosen to answer questions on the questionnaires in a particular way to please the experimenter in keeping with the 'social desirability bias' (Clifford, 1997).

A further potential weakness is that the researcher had to rely upon the participant concentrating on each question, being motivated, and in the right frame of mind to answer honestly (McLeod, 2001). Finally, participants may have engaged in other activities, which incidentally increased their self-compassion, well-being and resilience to stress and burnout.

\section{Conclusion}

This is an inaugural study which reports that student midwives who score high on selfjudgement have:

- Lower levels of compassion for self 
- Lower levels of compassion for others

- Lower levels of well-being

- Increased levels of burnout

- Increased levels of compassion fatigue

Since the numbers in this study were relatively small, there is opportunity to conduct a larger study that involves student midwives from multiple universities across the UK. Midwifery lecturers have a duty of care to explore this topic further, and if consistency in findings are reported, they could consider the possibility of utilising strategies to help equip students with the necessary tools to combat compassion fatigue and burnout. 


\section{References}

Abendorth, M., Flannery, J., 2006. Predicting the risk of compassion fatigue: a study of hospital nurses. Journal of Hospice \& Palliative Nursing 8, 346-356.

Andrews, B., Wilding, J.M., 2004. The relation of depression and anxiety to lifestress and achievement in students. British Journal of Psychology 95 (4), 509521.

Bakker, R.H., Groenewegen, P.P., Jabaaij, L., Meijer, W., Sixma, H.,de Veer, A., 1996. Burnout among Dutch midwives. Midwifery 12, 174-181.

Barad, J., 2007. The understanding and experience of compassion: Aquinas and the Dalai Lama. Buddhist-Christian Studies, 11-29.

Beaumont, E., Galpin, A.,Jenkins, P., 2012. Being kinder to myself: A prospective comparative study, exploring post-trauma therapy outcome measures, for two groups of clients, receiving either Cognitive Behaviour Therapy or Cognitive Behaviour Therapy and Compassionate Mind Training. Counselling Psychology Review. 27 (1), 31-43.

Beaumont, E., Hollins Martin, C.J., 2013. Using compassionate mind training as a resource in EMDR: A case study. Journal of EMDR Practice and Research. 7 (4), 186-199.

Beaumont, E., Hollins Martin, C.J., 2015. A narrative review exploring the effectiveness of Compassion-Focused Therapy. Counselling Psychology Review. 30 (1), 21-32.

Beaumont, E., Durkin, M., Hollins Martin, C. J., Carson, J., in press. Measuring relationships between self-compassion, compassion fatigue, burnout and wellbeing in trainee counsellors and trainee cognitive behavioural psychotherapists: a quantitative survey. Journal of Counselling and Psychotherapy Research

Benson, J., Macgraith, K., 2005. Compassion fatigue and burnout: the role of Balint groups. Australian Family Physician 34 (6), 497-498.

Blomberg, K., \& Sahlberg-Blom, E. 2005. Closeness and distance: A way of handling difficult situations in daily care. Journal of Clinical Nursing. 16, 244-254.

Boellinghaus, I., Jones, F.W., Hutton, J., 2012. The Role of Mindfulness and LovingKindness Meditation in Cultivating Self-Compassion and Other-Focused Concern in Health Care Professionals. Mindfulness 5, 129-138.

Braehler, C., Gumley, A., Harper, J., Wallace, S., Norrie, J., \& Gilbert, P., 2012. Exploring change processes in compassion focused therapy in psychosis: Results of a feasibility randomized controlled trial. British Journal of Clinical Psychology 52, 199 -214.

Brettle, A., Grant, M.J., 2004. Finding the evidence for practice: a workbook for 
health professionals. London: Churchill Livingstone.

British Medical Association. 2011. The Psychological and Social Needs of Patients. London: British Medical Association.

Brown, B., Crawford, P., Gilbert, P., Gilbert, J., Gale, C., 2013. Practical compassions: repertoires of practice and compassion talk in acute mental healthcare. Sociology of Health \& IIIness ISSN 0141-9889. pp. 1-17.

Brunetto, Y., Xerri, M, Shriberg, A, Farr-Wharton, R, Shacklock, K, Newman, S., Dienger, J. 2013. The impact of workplace relationships in engagement, wellbeing, commitment and turnover for nurses in Australia and the USA. Journal of Advanced Nursing, 1-14.

Care Quality Commission. 2011. The state of health care and adult social care in England. London: Stationery Office.

Clifford, C., 1997. Nursing and Health Care Research: A Skills-Based Introduction ( $2^{\text {nd }}$ ed.). London: Prentice Hall.

Crawford, P., Brown, B., Kvangarsnes, M., Gilbert, P., 2014.The design of compassionate care. Journal of Clinical Nursing 23 (23-24): 3589-99.

Crawford, P., Gilbert, P., Gilbert, J., Gale, C., Harvey, K., 2013. The language of compassion in acute mental health care. Qualitative Health Research 23, 719-727.

Davies, S., Coldridge, E., in press. 'No Man's Land': An exploration of the traumatic experiences of student midwives in practice. Midwifery http://dx.doi.org/10.1016/j.midw.2015.05.001

Evans, J., Macrory, I., Randall, C., 2015. Measuring well-being: Life in the UK 2015. Office for National Statistics. Available at: www.ons.gov.uk/well-being

Field, A., 2013. Discovering statistics using IBM SPSS statistics. London. Sage.

Figley, C.R., 1995. Compassion fatigue as secondary traumatic stress disorder: An overview. Compassion fatigue: coping with secondary traumatic stress disorder in those who treat the traumatized. New York: Brunner/Maze.

Figley, C.R., 2002. Treating compassion fatigue. New York: Brunner/Mazel.

Germer, C.K., Siegel, R.D., (eds.). 2012. Wisdom and Compassion in Psychotherapy: Deepening Mindfulness in Clinical Practice. Guilford: Guildford Press.

Gillespie, M., Melby, V., 2003. Burnout among nursing staff in accident and emergency acute medicine: a comparative study. Journal of Clinical Nursing $12,842-851$. 
Gilbert, P., 1997. The evolution of social attractiveness and its role in shame, humiliation, guilt and therapy. British Journal of Medical Psychology 70: 113147.

Gilbert, P., 2002. Evolutionary approaches to psychopathology and cognitive therapy. Special Edition: Evolutionary Psychology and Cognitive Therapy, Cognitive Psychotherapy: An International Quarterly 16: 263-294.

Gilbert. P., 2009. The Compassionate Mind. London: Constable.

Gilbert, P., 2010. Compassion Focused Therapy: The CBT Distinctive Features Series. London: Routledge.

Gilbert, P.,Procter, S., 2006. Compassionate mind training for people with high shame and self-criticism: Overview and pilot study of a group therapy approach. Clinical Psychology \& Psychotherapy 13, 353-379.

Gilbert, P., Clarke, M., Hemel, S., Miles, J.N.V., Irons, C., 2004. Criticizing and reassuring oneself: And exploration of forms, style and reasons in female students. British Journal of Clinical Psychology 43, 31-35.

Gillespie, M., Melby, V. 2003. Burnout among nursing staff in accident and emergency and acute medicine: a comparative study. Journal of Clinical Nursing 12 (6), 842-51.

Heffernan, M., Quinn, M.T., McNulty, R., Fitzpatrick, J.J., 2010. Self compassion and emotional intelligence in nurses, International Journal of Nursing Practice 16 (4), 366-73.

Hollins Martin, C.J., Forrest, E., 2013. Bereavement care for childbearing women and their families: an interactive workbook. Routledge, Abingdon, Oxon (UK).

Hollins Martin, C.J., Forrest, E., Wylie, L., Martin, C.R., 2013. The Understanding Bereavement Evaluation Tool (UBET) for midwives: factor structure and clinical research applications. Nurse Education Today 33: 1153-1159.

Hollins Martin C.J., Forrest, E., Wylie, L., Martin, C.R., 2014. An evaluative survey to assess the effectiveness of using an interactive workbook to deliver bereavement education to undergraduate student midwives. Midwifery 30, 942-948.

Hutcherson, C.A., Seppala, E.M., Gross, J.J., 2008. Loving kindness meditation increases social connectedness. Emotion 8, 720-724.

lles, V., 2011. Why reforming the NHS doesn't work: the importance of understanding how good people offer bad care. Really Learning. London.

Johnson, M., Long, T., 2007. Research ethics in the real world: issues and solutions for health and social care. Edinburgh: Churchill Livingstone Elsevier.

Joinson, C., 1992. Coping with compassion fatigue. Nursing 118-121. 
Kelly, A.C., Zuroff, D.C., Shapira, L. B., 2009. Soothing oneself and resisting selfattacks: The treatment of two intrapersonal deficits in depression vulnerability. Cognitive Therapy and Research 33, 301-313.

Kirkham, M., 2007. Traumatised midwives. AIMS Journal. 19(1). See: www.aims.org.uk/Journal/Vol19No1/traumatisedMidwives.htm (last accessed 15 July 2015)

Leary, M.R., Tate, E.B., Adams, C.E., Allen, A.B., Hancock, J., 2007. Selfcompassion and reactions to unpleasant self-relevant Events: The implications of treating oneself kindly, Journal of Personality and Social Psychology 92, 887-904.

Leaviss. J., Uttley, L., 2014. Psychotherapeutic benefits of compassion-focused therapy: an early systematic review. Psychological Medicine, p1-19. Cambridge University Press.

Leinweber, J., Rowe, H., 2010. The costs of 'being with the woman': secondary traumatic stress in midwifery. Midwifery 26, 76-87.

Lutz, A., Brefczynski-Lewis, J., Johnstone, T., Davidson, R.J., 2008. Regulation of the neural circuitry of emotion by compassion meditation: Effects of meditative expertise. PloS one 3, e1897.

McLeod, J., 2001. An administratively created reality: some problems with the issue of self-report questionnaire measures of adjustment in counselling/psychotherapy outcome research. Counselling and Psychotherapy Research 1, 215-226.

Mander, R., 2000. Perinatal grief: understanding the bereaved and their carers. In J. Alexander, C. Roth \& V. Levy (eds.), Midwifery Practice: Core Topics 3 (pp. 29-50). London: MacMillan

Maslach, C., Leiter, M.P., 1997. The truth about burnout: how organisations cause personal stress and what to do about it. San Francisco: Josey-Bass Publishers.

Maslach, C., Leiter, M.P., 2008. Early predictors of job burnout and engagement. Journal of Applied Psychology 93 (3), 498-512.

Mayhew S., Gilbert P., 2008. Compassionate mind training with people who hear malevolent voices. A case series report. Clinical Psychology and Psychotherapy 15, 113-38.

Miller, K.I., Stiff, J.B., Ellis, B.H., 1988. Communication and empathy as precursors to burnout among human service workers. Communication Monographs 55, 250-265.

Mollart. L., Skinner, V.M., Newing, C., Foureur, M., 2013. Factors that may influence midwives work-related stress. Women and Birth 26, 26-32. 
Neely, M.E., Schallert, D.L., Mohammed, S.S., Roberts, R.M., Chen, Y.J., 2009. Self kindness when facing stress: the role of self-compassion, goal regulation, and support in college students' well-being. Motivation and Emotion 33, 88-97.

Neff, K.D., 2003.The development and validation of a scale to measure selfcompassion. Self and Identity 2, 223-250.

Neff, K., Germer, C., 2012. A pilot study and Randomized Controlled Trial of the mindful self-compassion program. Journal of Clinical Psychology. PublishedWileyOnlineLibrary.

Neff, K.D., Hsieh, Y, Dejitterat, K., 2005. Self-compassion, achievement goals, and coping with academic failure. Self and Identity 4, 263-287.

Neff, K.D., Kirkpatrick, K.L., Rude, S., 2007.Accepting the human condition: Self-compassion and its links to adaptive psychological functioning. Journal of Personality 41, 139-154.

Nursing and Midwifery Council, 2015. The Code. Professional standards of practice and behaviour for nurses and midwives. Available at: http://www.nmcuk.org/code

Pfifferling, J.H., Gilley, K., 2000. Overcoming Compassion Fatigue. Family Practice Management 7 (4), 39-44.

Polit, D.F., Hungler, B.P., 1999. Nursing Research: Principles and Methods (6 ${ }^{\text {th }}$ ed.). Philadelphia: J.B. Lippincott.

Pommier, E.A., 2011. The compassion scale: dissertation abstracts international (Section A). Humanities and Social Sciences 72, 1174.

Raab, K., 2014. Mindfulness, self-compassion, and empathy among health care professionals: a review of the literature. Journal of Health Care Chaplaincy 20 (3), 95-108.

Ray, S.L., Wong, C., White, D., Heaslip, K., 2013. Compassion satisfaction, compassion fatigue, work life conditions, and burnout among frontline mental health care professionals. Traumatology 19 (4), 255-267.

Rockliff, H., Gilbert, P., McEwan, K., Lightman, S., Glover, D., 2008. A pilot exploration of heart rate variability and salivary cortisol responses to compassion-focused imagery. Clinical Neuropsychiatry 5, 132-139.

Sabo, B.M., 2006. Compassion fatigue and nursing work. Can we accurately capture the consequences of caring work? International journal Nursing Practice 12, 136-142.

Şenyuva, E., Kaya, H., Işik, B., Bodur, G. 2014. Relationship between self compassion and emotional intelligence in nursing students. International Journal of Nursing Practice 20 (6), 588-596. 
Sheen, K., Slade, P., Spiby, H., 2014. An integrative review of the impact of indirect trauma exposure in health professionals and potential issues of salience for midwives. Journal of advanced nursing 70 (4), 729-743.

Spickard, A. Gabbe, S.G., Christensen, J.F., 2002. Mid-career burnout in generalist and specialist physicians. Journal of the American Medical Association 288, 1447-1450.

Sprang, G., Clark, J.J., Whitt-Woosley, A., 2007. Compassion fatigue, compassion satisfaction, and burnout: Factors impacting a professional's quality of life. Journal of Stress and Trauma 12, 259-280.

Stamm, B.H., 2010. The Concise ProQOL manual, $2^{\text {nd }}$ ED. Pocatello, ID: ProQOL.org.

Stamm, B.H., 2009. Professional Quality of Life: Compassion Satisfaction and Fatigue Version 5 (ProQOL). /www.isu.edu/ bhstamm or www.proqol.org.

Tennant, R., Hiller, L., Fishwick, R., Platt, S., Joseph, S., Weich, S., Parkinson, J., Secker, J., Stewart-Brown, S., 2009. The Warwick and Edinburgh Mental Well-Being Scale (WEMWBS): Development and UK Validation. Health and Quality of Life Outcomes 5 (63), 1-13.

Todd, C.J., Farquhar, M. C., Camilleri-Ferrante, C. 1998. Team midwifery: the views and job satisfaction of midwives. Midwifery 14, 214-224.

Yoshida, Y., Sandall, J., 2013. Occupational burnout and work factors in community and hospital midwives: a survey analysis. Midwifery 29 (8), 921-6. 
Table 1: Mean and Standard Deviation scores for each scale

\begin{tabular}{cccc}
\hline Questionnaire & N & Mean & S.D \\
\hline CFOS & 102 & 3.86 & .73 \\
SCS & 102 & 2.89 & .67 \\
SJSs & 102 & 3.34 & .85 \\
SKSs & 102 & 2.61 & .91 \\
CS & 101 & 41.6 & 4.6 \\
CF/STS & 101 & 21.8 & 5.1 \\
BO & 101 & 22.9 & 4.8 \\
sWEMWBS & 101 & 24.6 & 4.2 \\
\hline
\end{tabular}

CFOS=Compassion for others scale. SCS=Self-Compassion Scale. CS=Compassion satisfaction, $\mathrm{CF} / \mathrm{STS}=$ Compassion fatigue/secondary traumatic stress, $\mathrm{BO}=$ burnout, sWEMWBS=The Short Warwick and Edinburgh Mental Well-being Scale. SJSs=Self-judgement subscale, SKSs=Selfkindness subscale. 
Table 2: Frequency of scores categorised as being low, average or high, on measures of compassion satisfaction, compassion fatigue and burnout

\begin{tabular}{cccc}
\hline ProQOL subscale & $\begin{array}{c}\text { Low } \\
\text { (22 and below) }\end{array}$ & $\begin{array}{c}\text { Average } \\
(23-41)\end{array}$ & $\begin{array}{c}\text { High } \\
\text { (42 and above) }\end{array}$ \\
\hline $\begin{array}{c}\text { Compassion } \\
\text { satisfaction } \\
\begin{array}{c}\text { Compassion } \\
\text { Fatigue }\end{array}\end{array}$ & $\mathrm{N} / \mathrm{A}$ & $44.6 \%$ & $56.4 \%$ \\
Burnout & 60.45 & $39.6 \%$ & $\mathrm{~N} / \mathrm{A}$ \\
& $49.5 \%$ & $50.5 \%$ & $\mathrm{~N} / \mathrm{A}$ \\
\hline
\end{tabular}


Table 3: Pearson's correlational scores for self-compassion, self-judgement and selfkindness in relation to burnout, compassion fatigue, compassion satisfaction, wellbeing and compassion for others.

\begin{tabular}{|c|c|c|c|c|c|c|c|c|}
\hline & $\begin{array}{l}\text { Compassion } \\
\text { for others }\end{array}$ & $\begin{array}{l}\text { Compassion } \\
\text { satisfaction }\end{array}$ & Burnout & $\begin{array}{c}\text { Compassion } \\
\text { fatigue }\end{array}$ & $\begin{array}{c}\text { Self- } \\
\text { kindness }\end{array}$ & $\begin{array}{c}\text { Self- } \\
\text { judgement }\end{array}$ & $\begin{array}{c}\text { Self- } \\
\text { compassion }\end{array}$ & $\begin{array}{l}\text { Well- } \\
\text { being }\end{array}$ \\
\hline $\begin{array}{l}\text { Compassion } \\
\text { for others }\end{array}$ & 1 & $\begin{array}{l}.166 \\
.096\end{array}$ & $\begin{array}{l}-.135 \\
.177\end{array}$ & $\begin{array}{l}-.225^{\star} \\
.024\end{array}$ & $\begin{array}{l}.186 \\
.061\end{array}$ & $\begin{array}{l}-.216^{*} \\
.029\end{array}$ & $\begin{array}{l}.132 \\
.186\end{array}$ & $\begin{array}{l}.172 \\
.085\end{array}$ \\
\hline $\begin{array}{l}\text { Compassion } \\
\text { satisfaction }\end{array}$ & $\begin{array}{l}.166 \\
.096\end{array}$ & 1 & $\begin{array}{l}-.593^{* *} \\
.000\end{array}$ & $\begin{array}{l}-.412^{* *} \\
.000\end{array}$ & $\begin{array}{l}.125 \\
.214\end{array}$ & $\begin{array}{l}-.170 \\
.089\end{array}$ & $\begin{array}{l}.201^{*} \\
.043\end{array}$ & $\begin{array}{l}.469^{\star *} \\
.000\end{array}$ \\
\hline Burnout & $\begin{array}{l}-.135 \\
.177\end{array}$ & $\begin{array}{l}-.593^{\star *} \\
.000\end{array}$ & 1 & $\begin{array}{l}.550^{* *} \\
.000\end{array}$ & $\begin{array}{c}-.203^{*} \\
.042\end{array}$ & $\begin{array}{l}.283^{* *} \\
.004\end{array}$ & $\begin{array}{c}-.312^{\star \star} \\
.001\end{array}$ & $\begin{array}{l}-.530^{* *} \\
.000\end{array}$ \\
\hline $\begin{array}{c}\text { Compassion } \\
\text { fatigue }\end{array}$ & $\begin{array}{l}-.225^{*} \\
.024\end{array}$ & $\begin{array}{l}-.412^{\star *} \\
.000\end{array}$ & $\begin{array}{l}.550^{* *} \\
.000\end{array}$ & 1 & $\begin{array}{l}-.130 \\
.194\end{array}$ & $\begin{array}{l}.233^{*} \\
.019\end{array}$ & $\begin{array}{c}-.192 \\
.054\end{array}$ & $\begin{array}{l}-.213^{*} \\
.033\end{array}$ \\
\hline $\begin{array}{c}\text { Self- } \\
\text { kindness }\end{array}$ & $\begin{array}{l}.186 \\
.061\end{array}$ & $\begin{array}{l}.125 \\
.214\end{array}$ & $\begin{array}{c}-.203^{*} \\
.042\end{array}$ & $\begin{array}{l}-.130 \\
.194\end{array}$ & 1 & $\begin{array}{l}-.570^{* *} \\
.000\end{array}$ & $\begin{array}{l}.581^{* *} \\
.000\end{array}$ & $\begin{array}{l}.408^{* *} \\
.000\end{array}$ \\
\hline $\begin{array}{c}\text { Self- } \\
\text { judgement }\end{array}$ & $\begin{array}{l}-.216^{*} \\
.029\end{array}$ & $\begin{array}{c}-.170 \\
.089\end{array}$ & $\begin{array}{l}.283^{* *} \\
.004\end{array}$ & $\begin{array}{l}.233^{*} \\
.019\end{array}$ & $\begin{array}{l}-.570^{* *} \\
.000\end{array}$ & 1 & $\begin{array}{l}-.607^{\star *} \\
.000\end{array}$ & $\begin{array}{l}-.374^{* *} \\
.000\end{array}$ \\
\hline $\begin{array}{c}\text { Self- } \\
\text { compassion }\end{array}$ & $\begin{array}{l}.132 \\
.186\end{array}$ & $\begin{array}{l}.201^{*} \\
.043\end{array}$ & $\begin{array}{l}-.312^{\star *} \\
.001\end{array}$ & $\begin{array}{l}-.192 \\
.053\end{array}$ & $\begin{array}{l}.581^{* *} \\
.000\end{array}$ & $\begin{array}{c}-.607^{* *} \\
.000\end{array}$ & 1 & $\begin{array}{l}.382^{* *} \\
.000\end{array}$ \\
\hline Well-being & $\begin{array}{l}.172 \\
.085\end{array}$ & $\begin{array}{l}.469^{\star \star} \\
.000\end{array}$ & $\begin{array}{l}-.530^{\star *} \\
.000\end{array}$ & $\begin{array}{c}-.213^{*} \\
.033\end{array}$ & $\begin{array}{l}.408^{\star *} \\
.000\end{array}$ & $\begin{array}{c}-.373^{* *} \\
.000\end{array}$ & $\begin{array}{l}.382^{* *} \\
.000\end{array}$ & 1 \\
\hline
\end{tabular}

${ }^{* \star} \mathrm{p}<.001$ level (2-tailed). ${ }^{\star} \mathrm{p}<.005$ level (2-tailed). 
Table 4: Independent samples t-test results for high versus low self-judgement scores in comparison to compassion, compassion satisfaction, compassion fatigue, burnout and well-being.

\begin{tabular}{ccccc}
\hline Scale & $\begin{array}{c}\text { Low self- } \\
\text { judgement }\end{array}$ & $\begin{array}{c}\text { High self- } \\
\text { judgement }\end{array}$ & $\mathbf{t}$ & p-value \\
\hline $\begin{array}{c}\text { Compassion for } \\
\text { others }\end{array}$ & $4.2(.94)$ & $3.6(.69)$ & 2.23 & .05 \\
$\begin{array}{c}\text { Compassion } \\
\text { satisfaction }\end{array}$ & $42.4(5.1)$ & $40.6(4.6)$ & 1.27 & ns \\
$\begin{array}{c}\text { Compassion } \\
\text { fatigue }\end{array}$ & $20.0(5.2)$ & $23.2(5.9)$ & -1.81 & ns \\
Burnout & $20.6(4.4)$ & $24.2(5.4)$ & -2.27 & .05 \\
Well-being & $27.4(3.7)$ & $23.2(4.7)$ & 3.08 & .01 \\
\hline
\end{tabular}

